\title{
WHY DIDN'T THE WATCHDOGS BARK? INTERNAL AUDITING AND THE WELLS FARGO SCANDAL
}

\author{
ELENA ANTONACOPOULOU \\ GNOSIS / University of Liverpool Management School \\ Liverpool L69 7ZH - UK \\ REGINA F. BENTO \\ University of Baltimore \\ LOURDES F. WHITE \\ University of Baltimore
}

INTRODUCTION

"Every word has consequences. Every silence, too." (Sartre, 1945: 5)

Professional misconduct and scandal persist in the financial services industry, in spite of increasing regulation and efforts by professional associations and organizations. This paper focuses on a particular group of professionals -- internal auditors -- who are explicitly supposed to be "watchdogs" (Roussy, 2013), entrusted with the formal responsibility of sounding the alarm about the risk of fraud and corporate misconduct and wrongdoing, in order to deter, detect, and denounce such frauds and keep them from evolving into full-fledged scandals. Our goal here is not to examine who originally committed a specific fraud and why, but to ask: "how can we explain the silence of internal auditing amid increasing signs that fraud is arising and spreading within an organization?"

We explore this broader question in the particular context of why internal auditing seems to have remained remarkably silent as the cross-selling fraud at Wells Fargo's Community Bank Division unfolded and grew over the years, finally blossoming into a massive, wide-open scandal in 2016 that is still reverberating in 2019. In particular, we explore how even well-meaning and well-trained "watchdogs" might be sidetracked by three time-honored professional tenets in accounting and auditing: scope, compliance and materiality. These three tenets are deeply ingrained in the socialization and training of internal auditors, are foundational for the daily practice of their profession, and are critical in managing the shifting and contested boundaries of internal auditing. We propose that the complexity and internal tensions inherent in these three tenets may also lead to unintended consequences, creating conditions where the "watchdogs" may not bark even when they know, or should have known, that other members of the organization are engaging in fraud.

\section{THE WELLS FARGO SCANDAL}

Wells Fargo was founded in 1852 with a mission to serve the fast-growing Western region of the United States. Headquartered in San Francisco, the bank grew to be the third largest US bank in terms of total assets. Hailed for its consistent performance, even as other banks struggled to earn returns above their cost of capital after the global financial crisis of 2008 (Ip, 2016), Wells Fargo in 2016 boasted the largest return on equity among US banks (Glazer, 
2016b). In 2016, however, Wells Fargo's unbridled focus on growth combined with a highlydecentralized culture ultimately led the bank to a widespread sales-related fraud that was voted "scandal of the year" by the readers of The Wall Street Journal (2016).

The fraud was motivated by intense pressure to meet increasingly aggressive cross-sales targets in Wells Fargo's Community Bank (CB) division. CB's retail operations accounted for about half of Wells Fargo revenues and profits (Rapoport 2016a). Starting in 2007 (and consistent with questionable sales practices dating before 2002), managers set ambitious crosssales targets; sales performance was the basis for promotions and recognition, and failure to achieve targets could result in termination. Under the tremendous pressures of this environment, $\mathrm{CB}$ employees resorted to opening accounts for fictitious customers, or using information from current customers to create new accounts without customers' knowledge or consent. They also engaged in simulated funding, by transferring funds from existing accounts to the unauthorized accounts, in order to meet minimum deposit requirements and earn sales-related incentives. Some employees transferred their own money temporarily into new accounts to demonstrate growth in deposits. As problems with sales integrity expanded between 2007 and 2013, Wells Fargo's funding rate (the percentage of new accounts that meet minimum deposit requirements) dropped from $90 \%$ in 2005 to $80 \%$ in 2012 (Wells Fargo Board, 2017). The unethical sales practices involved area presidents, district managers, branch managers and personal bankers (sales employees with direct customer contact); as one employee described "it became pretty normal" (Glazer, 2017). An estimated 3.5 million accounts were affected.

By 2017, it was estimated that 5300 employees had been involved in creating fake accounts and most of Wells Fargo's 6000 branches were affected. Two areas with high clusters of sales-related violations were California and Arizona. By some estimates, 85,000 accounts were charged about $\$ 2$ million in overdraft fees as a result of simulated funding (Hayashi, 2016). The bank did not directly benefit from these accounts, because they resulted in few revenueearning transactions and, eventually, Wells Fargo had to refund $\$ 2.5$ million to customers for overdraft fees (Hayashi, 2016). As the Wells Fargo scandal unfolded in the public domain during 2016, with the bank charged to pay $\$ 185$ million in penalties and fines, shareholders' confidence suffered, with Wells Fargo stock losing almost $10 \%$ or $\$ 23$ billion in market value (Rapoport, 2016a). Wells Fargo's biggest investor, Warren Buffett, who owned 10\% of Wells Fargo, stated the sales fraud problem was bigger than the CEO reported, and public reaction should not be measured by the current size of the fines (Glazer, 2016b). This prediction was confirmed in December 2018, when the bank settled investor lawsuits for $\$ 480$ million. Large customers such as several state and city governments suspended businesses with Wells Fargo; the states of California and Illinois, and the city of Chicago were among the first (Ochs, 2016). Customers large and small were legitimately feeling betrayed in their confidence placed on a bank that misused their personal information for personal gain.

In the fall of 2016, the CEO John Stumpf and other high level executives resigned; the head of retail banking was fired in July 2016. The Board clawed back over $\$ 183$ million in incentives paid out to current and former executives in connection with sales performance (Glazer \& Lublin, 2017). The bank ended its sales incentive policies and product-sales goals, separated the positions of CEO and Chairman of the Board, and created stronger control and risk groups, tasked with surprise bank branch audits and tighter surveillance of accounts. In October 2018, the Chief Administrative Officer and Chief Auditor went on leave amid regulatory warnings. Investigations were launched by the United States Justice Department, the SEC and several federal and state regulators, and, by the end of 2018, Wells Fargo agreed to pay $\$ 575$ 
million to settle these investigations. In addition to these reverberations, the scandal had a profound effect on the public image of Wells Fargo. After the 2008 financial crisis, Wells Fargo had "held itself apart from its New York-based peers (...) and regularly touted its 'culture of caring.' The public believed it, rating the brand far more trustworthy than any of its peers of a similar size." (Ochs, 2016). But by 2018, when Wells Fargo tried to "re-establish" this trust after the scandal, the public found it harder to believe.

In total, our interdisciplinary team analyzed over 2,000 pages of documents (not counting other materials available online). We collected data on the Wells Fargo cross-sales wrongdoing from December 2013 through April 2017, and news articles through January 2019. The salesrelated fraud dated back to 2002 but its results only became public when the Los Angeles Times first published a series of articles about sales practice violations in December 2013. At the time of this writing, in January 2019, reverberations from the case are still making front-page news.

\section{TENETS OF INTERNAL AUDITING AND THE WELLS FARGO SCENARIO}

In the socialization and daily practice of IAs three professional tenets influence and determine, to a large extent, how they will manage conflicting roles and shifting, contested boundaries. These tenets comprise: scope (before the work starts, the IA knows what areas are within and outside the scope of the audit); compliance (while conducting the audit, the IA tests if actual controls comply with regulations and standards); and materiality (if a control weakness is found, the IA decides if it is material or not).

\section{Scope}

The scope of an audit delineates the time frame and types of activities and documentation the IAs will examine, based on the range of oversight set by the Audit Committee of the Board of Directors, in consultation with senior management. This scope planning is intended to improve efficiency and reduce duplication of efforts of IAs with respect to other groups, e.g. risk management, human resources, and the external auditors. While assurance over internal controls is usually a main focus of IA, Audit Committees are responsible for continually assessing risk changes in the environment and adjusting the scope of internal audit accordingly (KPMG, 2017).

At Wells Fargo, IA considered itself the "third line of defense" in detecting and preventing fraud (Roussy \& Rodrigue, 2018). The first line of defense resided at the business unit level (in this case, the Community Bank division - CB), and the second line of defense consisted of risk management oversight at the corporate level (Wells Fargo Board, 2017: 93). IA assumed that the scope of investigating sales malpractice was ascribed to other groups inside and outside the bank. IA's narrow definition of scope may have contributed to its lack of responsiveness to the sales malpractice, and to its reliance on other professionals in the ecology of gatekeepers, both inside and outside the organization.

IAs at Wells Fargo reported to the CEO (who was also chairman of the board) and failed to provide the Audit Committee with reasonable assurance regarding corporate governance and internal controls. The Board did not expand IA's scope even after receiving the results of several investigations, and lacked independence. Wells Fargo had the longest-serving and oldest directors among other large US banks (Gray, 2016).

IA's resistance against going outside of the scope of its audits to investigate the sales fraud in CB is all the more surprising against the backdrop of public scrutiny of Wells Fargo's 
sales irregularities during 2013-2016. In December 2013, the Los Angeles Times reported questionable sales practices by Wells Fargo offices in Southern California; the IAs verified that $\mathrm{CB}$ in the Los Angeles area had started its own investigations, "which gave Audit comfort that the monitoring systems could appropriately detect problematic conduct." (Wells Fargo Board, 2017: 92). The Los Angeles City Attorney Office launched its own investigation of Wells Fargo, culminating with a lawsuit in May 2015, where Wells Fargo was charged with pressuring retail employees to commit fraud. Wells Fargo hired the accounting firm PricewaterhouseCoopers (PwC) to do in-depth analysis of questionable sales and simulated funding, and $\mathrm{PwC}$ found evidence of fraud in several regions.

Throughout 2015, the United States Consumer Financial Protection Bureau (CFPB) pressed Wells Fargo for answers. Other federal regulators such as the Office of the Comptroller of the Currency (OCC) notified Wells Fargo that they needed to investigate all allegations and respond diligently. The bank responded by hiring consultants and legal counsel; CB responded by lowering sales goals and strengthening new account controls, but wrongdoing persisted.

During 2002-2016, IAs consistently accepted the scope limitations of their audits and relied on $\mathrm{CB}$ to do its own investigations and remedy the situation. Ironically, this confined scope may have had the beneficial effect of constraining its silent acquiescence from unduly influencing other professionals. The limitations in internal audit's scope played a role in muting (at least for a while) the reactions of Wells Fargo's broader network of gatekeepers. Wells' own corporate lawyers, and external professional firms in law, external auditing and consulting, plus rating agencies, securities analysts, regulators and others seem to have over-relied on an uncritical, passive acceptance of Audit's performance as a reliable watchdog.

In the face of all the warning signs at Wells Fargo IAs remained silent. This type of professional silence (Milliken, Morrison \& Hewlin, 2003; Morrison, 2014; Morrison \& Milliken, 2000) persisted, even though the formal role of internal auditors required more from them, in terms of denouncing possible fraud and wrongdoing, than from other employees. Despite many reasons to blow the whistle (Grant, 2002; Miceli, Near \& Dworkin, 2013), no IAs decided to become whistleblowers. Even if IAs did not know what was going on, they should have known. Therefore, they were at the very least sidetracked by ethical blind spots (Bazerman \& Tenbrunsel, 2011b; Bazerman, Moore, Tetlock \& Tanlu, 2006; de Klerk, 2017; Watkins \& Bazerman, 2003). IA at Wells Fargo considered the CEO (and not the Board) as its main "client." The CEO was publicly defending cross-sales as a winning strategy, so it is not surprising that IA may have succumbed to "motivated blindness" (Bazerman \& Tenbrunsel, 2011a).

\section{Compliance}

Since the Sarbanes Oxley (SOX) Act of 2002, US public companies are required to audit internal controls to ensure that the appropriate procedures are in place "to detect significant errors, irregularities and material weaknesses in internal control." (KPMG, 2017). IAs are responsible for assuring that, in compliance with SOX, the internal accounting controls are: 1) present; 2) functioning; and 3) effective (COSO, 2013). IAs should be in the best position to serve as expert gatekeepers with respect to compliance of internal controls (Alzola, 2017): IAs have technical training in accounting and systems, access to privileged information from within business units, and motivation to preserve their reputational capital by avoiding legal liability (Coffee, 2006). While several checklists exist to guide IAs towards compliance with the first two 
criteria, internal auditors are required to "... apply judgment as they monitor and assess the effectiveness of the system of internal control." (COSO, 2013:1). IAs, led by the Chief Audit Executive (CAE), assist the CEO and CFO, who are ultimately responsible for the integrity of the controls. Reports of control weaknesses need to be submitted to the Audit Committee of the Board. IAs thus "... wear two hats: one of a team member and confidant, and the other of a watchdog or police cop.” (Merchant \& Van der Stede, 2012: 619).

At Wells Fargo, it can be argued that internal auditors' roles were less as watchdogs than helpers and protectors of top managers (Roussy, 2013; Roussy \& Perron, 2018). Assessment basically relied on checklists to detect if mandatory controls were present and functioning. When checking for compliance, IAs did not visit the branches directly, but relied mostly on CB's own audit visits to branches, despite the fact that branch managers were warned 24 to 72 hours in advance of the visits, with plenty of time for shredding documents and forging signatures (Glazer, 2017). Furthermore, IAs did not review allegations of fraud and continued assessing the bank's compensation system and its associated risks by inspecting plan documents, with no field visits nor interviews. Fundamentally, the evidence shows that IA continued rating the controls at $\mathrm{CB}$ as "Effective" for compliance purposes even though the controls were ineffective in reducing the risk of fraudulent sales. A special concern was that Wells Fargo did not mention cross-selling irregularities in its second quarter financial reports released in August 2016, even though management was already negotiating with regulators a settlement that became public in September 2016.

While there is no direct evidence that IA's objectivity and independence were hampered by complicity with Wells Fargo management, it is clear that a simple "compliance checking process" (Chambers \& Odar, 2015: 38) with regulations such as SOX was not enough to enable Audit to challenge the CEO regarding real risks with sales fraud. Rather than being the messengers of bad news, IAs at Wells Fargo remained silent about multiple investigations, complaints, repeated findings, and integrity violations. As in the Sherlock Holmes story (Doyle, 1902), the very fact that these watchdogs did not bark is a significant aspect of the Wells Fargo debacle.

\section{Materiality}

According to the Financial Accounting Standards Board (FASB)'s Statement of Financial Accounting Concepts (SFAC) no. 8 "information is material if omitting it or misstating it could influence decisions that users make on the basis of the financial information of a specific reporting entity." (FASB, 2010). Materiality is a concept of great practical importance because it helps accounting professionals judge when certain transactions need to be reported to various users, and, in the context of audits, whether a questionable amount is worth investigating. It also assists organizations trying to allocate the limited attention and resources of their auditing professionals to problems of real importance.

However, materiality may seem like a misleadingly simple concept: when applied in practice, there is a critical need for auditors to employ good professional judgment to decide, in complex settings, what constitutes material information. This need for professional judgment has been emphasized by the Securities and Exchange Commission (SEC) and other regulators. In August 2018 the FASB issued an Amendment to its Concepts Statement no.8, highlighting the importance of not relying just on quantitative indices and thresholds but also on qualitative judgment, which takes into account surrounding circumstances. 
Professional judgment should make IAs wary of relying on the tempting simplicity of the heuristic approach commonly used in practice, whereby an event is typically considered immaterial if it accounts for less than 5\% of earnings (Mintz \& Morris, 2017). An IA adopting this heuristic could miss wrongdoing that impacts, say, $4 \%$ of income. Simple quantitative thresholds for materiality can thus act as Harry Potter's invisibility cloak, covering wrongdoing and misconduct.

IAs at Wells Fargo treated the events related to sales fraud at CB as immaterial, even though the situation actually met all three qualitative criteria established by the SEC for materiality: the sales practices affected regulatory compliance (as argued in the previous section), they involved illegal activities such as forging documents and destroying evidence; and allowed managers to earn incentive compensation for their wrongdoing. KPMG, Wells Fargo's external auditor, also argued that the sales practice irregularities were immaterial and thus had no effect in KPMG's audit opinion of the integrity of Wells Fargo's financial reports and internal controls (Rapoport, 2016c, 2016d).

Materiality should, however, have been recognized in this case, as evidenced by the reactions from stakeholders outside Wells Fargo. Even though Wells Fargo did not admit to fraud, the reputational losses were material. How then could the IAs deem the irregularities immaterial over a period of more than 10 years, in a situation where sales misconduct led federal and state regulators to launch investigations, led the CEO and top executives to resign, and led the stock price to drop 10\%? The IAs seemed to have suffered from the "identifiable victim effect" (Jenni \& Loewenstein, 1997). They were probably very aware of how CB "needed" to keep the pressure to cross-sell; if the IAs blew the whistle on this practice, CB leaders believed that the division (and, consequently, Wells Fargo as a whole) would likely not remain competitive in a financial industry that was still suffering the effects of the global crisis of 2008. Conversely, Wells Fargo customers were the unidentified victim of immaterial sales practices, according to the internal and external auditors who judged materiality on quantitative terms only.

\section{CONCLUSION}

A common underlying assumption in the study of professional misconduct is that it fundamentally consists of a departure from professional norms, rules, standards and codes of ethics. Here we explored an alternative possibility: that misconduct might not necessarily involve a departure from sound profession tenets, but rather a misguided adherence to them. Our analysis of the Wells Fargo scenario illustrates how the misapplication of three key tenets of the internal auditing profession - scope, compliance and materiality -may have dysfunctional effects, helping to explain why internal auditing remained remarkably silent, for quite a long time, about rampant and increasingly public fraud in the Community Bank Division - all the while remaining arguably within the boundaries defined by these three tenets. Our hope is that problematizing tenets that may keep watchdogs from barking can ultimately encourage IAs to watch their own practices more closely, to avoid the organization-wide blind spots that continue to blindside Wells Fargo. As Sartre reminds us in our opening quote, both the words and the silence of internal auditing professionals may have very real consequences for individuals, organizations and society.

\section{REFERENCES AVAILABLE FROM THE AUTHORS}

